\title{
A Comparative Study of Neurocognitive Impairment in Elderly Patients with Schizophrenia and Elderly Normals
}

\author{
Nawab Akhtar Khan*, Amrita Kanchan**, Archana Singh***, K.S. Sengar**, A.K. Nag**** \\ * Clinical Psychologist, DMHP, Gumla; (Jharkhand), ** Department of Clinical Psychology, ***Department of \\ Psychiatric Social work, **** Department of Psychiatry, RINPAS, Kanke, Ranchi
}

\begin{abstract}
Background: Cognitive impairment has been known to be a feature of Schizophrenia since the illness was first described in a systematic manner. The course of cognition and functional status in schizophrenia remains an area of significant controversy and is marked by conflicting findings. One of the reasons for this controversy is that cognitive and functional changes occur with normal aging in the population.

Method: Total number of samples in the study were 80 (experimental and control), out of which 40 were elderly schizophrenic patients and 40 were normal elderly individuals. Elderly patients with schizophrenia were selected from the inpatient department of RINPAS, Ranchi. Normal elderly people were selected from near by areas of the hospital. On both the groups the Post Graduate Institute- Battery for Assessment of Mental Efficiency in Elderly (PGI- AMEE) test was administered.

Result: Significant differences were found in mental efficiency between normal elderly group and elderly schizophrenic patients. The mean score of normal population is 52.90 and for schizophrenic group 40.20.

Conclusion: The findings of the index study suggests that the marked differences in cognitive functioning has been found between elderly patient with schizophrenia and normal elderly people .Areas of impairment were difficulty in recalling names of different things, general orientation and visuo-spatial coordination.
\end{abstract}

Keywords: Cognitive assessment, Cognitive Impairment, Schizophrenia

\section{INTRODUCTION}

The current literature in psychiatry reveals many studies dealing with the relationship between schizophrenia and cognitive deficits. Since long back it was talked by researcher that patient with

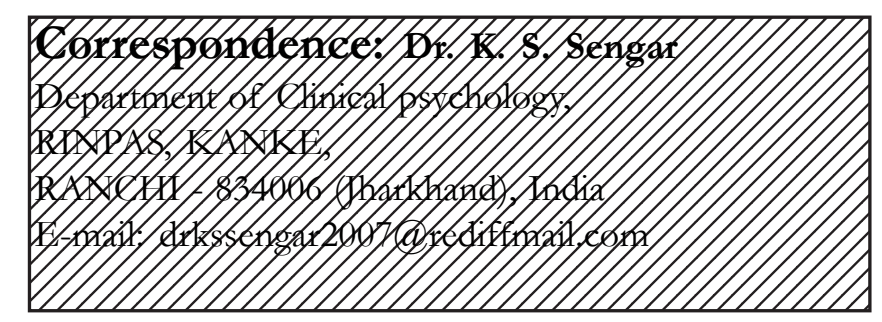

schizophrenia are having impact on the development of personality and cognition and it significantly affect the functioning of the individual. Cognitive impairments are common in schizophrenia ${ }^{1}$ since long back psychological and cognitive deterioration was the centre of the literature of schizophrenia. But the cause of cognitive and functional status in schizophrenia is stills a controversial issue. Age of onset of the illness, duration of the illness, and types of symptomatology has significantly contributed in the outcome, maintenance, relapse and psychosocial rehabilitation of the patients ${ }^{2,3}$. Although the 
pathophysiological mechanism of the observed progression of cognitive impairments in poor outcome schizophrenia patients have not yet been elucidated, rather risk factors for poor outcome have been identified. Lower levels of education and poorer premorbid adjustment are positively associated with a poorer outcome at follow up. Educational status plays a role in out come in late life as well. A prospective study of the geriatric schizophrenic patient's who developed moderate to severe cognitive impairment over a 30 months follow up revealed that patient's with lower levels of education were at significantly greater risk for this decline. It has been demonstrated that early intervention with antipsychotic medication may reduce some of the long term morbidity associated with Schizophrenia ${ }^{4}$.

Prior works related to present study shows cognitive impairment takes place due to many reasons, Patients who demonstrate more severe cognitive deficits have been found to be more likely to be unemployed ${ }^{5,6}$, to be chronically institutionalized ${ }^{7}$, to have impaired basic self-care skills ${ }^{8,9}$, and to be unable to benefit from psychiatric rehabilitation $^{10,11,12}$. Similarly, negative symptoms have been found to be associated with functional disability and poor outcome ${ }^{3,9}$. Because cognitive deficits and negative symptoms appear to be correlated in their severity, the differential association between negative and cognitive symptoms and outcome requires close attention. In a longitudinal study there were cross-sectional correlations between the severity of negative symptoms and cognitive symptoms ${ }^{13}$ but no longitudinal relationships between these aspects of the illness was confirmed. In contrast, there is little evidence of any appreciable relationship between the severity of the positive symptoms and negative and cognitive symptoms and aspect of functional outcome.

The instrumental and social skills deficits were studied and results reveal the strong correlation of instrumental and social skills deficits with cognitive impairments than with the severity of under controlled behavior. Each of the cognitive measures was correlated with global social-adaptive deficits, with minimal variation in the magnitude of correlations ${ }^{14}$.
The outcome of schizophrenia in old age remains among the most debated topics in schizophrenia research. The debate between the Kraepelinian pronouncement that the outcome is invariably bleak, and the view that the outcome of schizophrenia in old age is variable, focuses on the schizophrenic's cognitive capacities in old age and not on the psychosis, which for many (but not all) patients ameliorates. There is consensus among investigators that nearly all young and middle-aged schizophrenic patients suffer from moderate cognitive impairment, and that a certain proportion of geriatric patients suffer from a very severe form of cognitive impairment. There is, however, no consensus on the proportion of geriatric schizophrenic patients who suffer from the severe form of cognitive impairment, on the specific manifestations of the cognitive impairment in old age, or on how moderate impairment of specific cognitive aspects progresses, if at all, into severe and possibly global cognitive impairment.

Thus, keeping in mind the studies regarding cognitive and functional deficit in elderly patients with schizophrenics and various controversies regarding it; an attempt is made to study various cognitive deficits in elderly patients with schizophrenics and how is it different from normal elderly population.

\section{METHODOLOGY \\ Sample}

The present study consisted of 40 elderly patients with schizophrenia and 40 normal controls. The study was carried out at Ranchi Institute of Neuropsychiatry and Allied Sciences (RINPAS), Ranchi, India. Patients were diagnosed as case of Schizophrenia according to International Classification of Disease-10 (ICD10, DCR Criteria, WHO, 1993). Patients falling in the age range of 55 and above, and who were cooperative and literate were included in the study. Patients who had co morbid psychiatric disorder, vision and hearing impairment, history suggesting organic pathology, substance abuse and mental retardation or significant physical illness were excluded from the study. For normal control, 40 individuals who were literate, cooperative and falling 
in the age range of 55 and above were chosen for the study. Individuals with significant physical problem, having a history of seizure/ severe head injury or any other neurological problems, who had faced any traumatic event in last 3 months, illiterate and who were uncooperative were excluded from the study.

\section{Tools}

\section{Socio-Demographic and Clinical Data Sheet:}

It is a semi-structured proforma especially designed for the study. It contains questions regarding details of the age, education, and brief family background, duration of stay in the institution and nature of illness.

General Health Questionnaire-12 (David Goldberg \& Paul Williams, 1988) ${ }^{15}$ :

The test consists of 12 questions. It was used to identify and exclude the individuals for normal control group.

\section{Positive and Negative Symptoms Checklist} (PANNS, Kay et. al. 1987) ${ }^{16}$ :

This checklist contains relevant areas to assess the severity of the symptoms. It is 7 point scale divided in three sub-scales-Positive scale, Negative scale and General psychopathology scale. It was used to assess the psychopathology of the patients. Individuals with active psychopathology were excluded from the study.

PGI- Battery for Assessment of Mental Efficiency in the Elderly (PGI - AMEE, Kohli, Verma \& Prasad, 1993).

The Test is basically used to assess the cognitive functioning of individuals falling in the age range of 55 years and above. The important dimensions of this test are: Mental efficiency motivation and alertness, general information, general orientation to time and place, memory, concentration, perceptual- motor functions including depth perception and muscular coordination, and finally depressive mood associated with old age.

\section{Procedure:}

After screening patients according to inclusion and exclusion criteria, they were selected for the study. Clinical interview and required history was taken and socio-demographic and clinical data sheet were filled. Information was cross-checked from the case record file wherever required. Further Positive and Negative Symptoms Scale (PANSS) was administered to screen patients with active psychopathology. Finally Post Graduate Institute Battery for Assessment of Mental Efficiency in Elderly (PGI- AMEE) was administered to assess the cognitive functioning of schizophrenic elderly patients. Similar procedure was applied for normal elderly control group individuals; GHQ-12 was used to screen out persons who were physically and mentally fit. Further PGI-AMEE was administered to assess the cognitive functioning of normal control individuals.

\section{RESULTS}

The socio-demographic variables of the subjects are mentioned in Table 1. The results show that there was no significant difference in any domain in both groups.

\section{Table 1: Socio demographic variables}

\begin{tabular}{|c|c|c|c|c|c|}
\hline S.No. & \multicolumn{2}{|c|}{ Variables } & $\begin{array}{c}\text { Normal group } \\
\quad(40)\end{array}$ & $\begin{array}{l}\text { Patient } \\
\text { group } \\
\text { (40) }\end{array}$ & $\chi^{2}$ \\
\hline \multirow{3}{*}{1.} & \multirow{3}{*}{ Age in years } & $55-59$ & 16 & 17 & \multirow{3}{*}{$.13 \mathrm{NS}$} \\
\hline & & $60-64$ & 13 & 12 & \\
\hline & & $\begin{array}{ll}65 & \text { and } \\
\text { above }\end{array}$ & 11 & 11 & \\
\hline \multirow{2}{*}{2.} & \multirow{2}{*}{ Sex } & Male & 20 & 20 & \multirow{2}{*}{$.04 \mathrm{NS}$} \\
\hline & & Female & 20 & 20 & \\
\hline \multirow{3}{*}{3.} & \multirow{3}{*}{$\begin{array}{l}\text { Education in } \\
\text { years }\end{array}$} & $0-5$ years & 16 & 17 & \multirow{3}{*}{$.04 \mathrm{NS}$} \\
\hline & & 6-9 years & 16 & 15 & \\
\hline & & 10and above & 8 & 8 & \\
\hline \multirow{2}{*}{4.} & \multirow{2}{*}{ Marital status } & Married & 39 & 36 & \multirow{2}{*}{$.03 \mathrm{NS}$} \\
\hline & & Unmarried & 1 & 4 & \\
\hline \multirow{3}{*}{5.} & \multirow{3}{*}{ Religion } & Hindu & 33 & 30 & \multirow{3}{*}{$1.8 \mathrm{NS}$} \\
\hline & & Muslim & 7 & 7 & \\
\hline & & Christian & 0 & 3 & \\
\hline \multirow{3}{*}{6.} & \multirow{3}{*}{ Domicile } & Rural & 19 & 17 & \multirow{3}{*}{$.24 \mathrm{NS}$} \\
\hline & & Urban & 8 & 8 & \\
\hline & & Semi urban & 13 & 15 & \\
\hline \multirow{2}{*}{7.} & \multirow{2}{*}{ Family type } & Joint & 37 & 34 & \multirow{2}{*}{$.2 \mathrm{NS}$} \\
\hline & & Single & 3 & 6 & \\
\hline
\end{tabular}

Table - 2 Mental Efficiency of Elderly Schizophrenic Group and Elderly Normal Control Group

\begin{tabular}{|l|c|c|c|}
\hline \multicolumn{1}{|c|}{ Group } & Mean Score & $\chi^{2}$ & Level of Significance \\
\cline { 1 - 2 } Normal elderly population & 52.90 & \multirow{2}{*}{29.23} & .01 level \\
\hline $\begin{array}{l}\text { Schizophrenic elderly } \\
\text { population }\end{array}$ & 40.20 & & \\
\hline
\end{tabular}


Above mentioned Table -2 reveals the mental efficiency of both groups. Significant difference was found between the mental efficiency of normal elderly individuals and elderly patients with schizophrenia. The mean score of normal population is 52.90 and for schizophrenic group 40.20, it shows that individuals who are not suffering from schizophrenia illness has scored better in the test, specially in the areas as orientation, visuo-spatial movement and set test, which indicates that the mental functioning of normal group is better than the schizophrenia group.

\section{DISCUSSION}

It is evident that most component processes of cognition decline with advanced age if the difficulty level is sufficiently high. The examples will include the processes involving attention, working memory capabilities (the amount of information you can work without losing track of any), understanding text, making inferences, encoding (putting information into memory) and retrieval ${ }^{17,18,19}$. Severe cognitive impairment have also been reported in large numbers of geriatric chronic schizophrenic patients, this impairment also being found related to severe negative symptoms and adaptive deficits ${ }^{7}$, but the question arises is, whether the cognitive impairment in schizophrenic patients is the results of old age or the result of chronic illness. The results of the present study show that elderly schizophrenic patients have significant cognitive impairment in comparison to normal elderly population.

Poor performance of schizophrenia group may be due to poor information processing, reduced interaction pattern as well as lack of opportunity to interact with external environment. Result reveal that cognitive impairment in adaptive functioning in patient with aged schizophrenia has strong predictor of poor outcome. Samples of present study were institutionalized patients and many past studies on institutionalized patients conducted all over the world, also reveal similar findings. Schizophrenic patients who reside in chronic psychiatric hospitals, over 50\% suffered from sever impairment in more than one area of cognition which affects their social functioning ${ }^{2}$.

The results of present study reveal severe cognitive impairment among elderly schizophrenics in areas such as visuo-spatial task, general orientation and recall of the items of set test. It may be the results of

long term institutionalization, where schizophrenic patients hardly interact with others, sit alone \& aloof. They are poorly motivated to take any initiative. So they are not willing to gather information about the world and excessively detached from the society and current events, which is an essential phenomenon for improving their orientation about time, place, person, day, dale, month, year etc.

Long term institutionalization also affects their motivation level. This can reduce their ability to take initiative, ability to use mental functions and ability to generate new ideas, which are required for better information processing and development of new concepts. Poor performance on visuo-spatial task may be because of poor ability, poor ability to plan and organize information in a rational manner. However poor vision and extra pyramidal symptoms may be caused by antipsychotic, which might have cobbled some of the patent's performance.

Persistent institutional social environment contribute to the cognitive impairment. But some researchers are not in the favour of similar findings they found that long term deinstitutionalization also has the causal relationship in worsening the cognitive functions in patient with positive symptoms. The possible cause might be the poor family support, poor drug complaints, infrequent consultation to therapist and poor job involvement ${ }^{2}$.

The type of the symptoms (positive $\&$ negative) persists has the significant place in the cognitive impairment of schizophrenic patient. As patient with negative symptom has markedly poor personal care \& hygiene, retarded psychomotor activities, restricted or flat affect, increased reaction time etc. They are unable to take care of themselves and orient to the outer world. Due to long term hospitalization they need more supervision than the patient with positive symptoms. On the other side patients with positive symptoms having active hallucination, are least concerned with outer world and are always busy with their hallucinatory content. They make their own world, which significantly hamper their interaction with the outer world, which further causes stimulation of restricted area of the brain. Over all outcomes is that both 
positive \& negative symptoms of the illness have impairment in both adaptive and cognitive functioning ${ }^{14}$.

In the light of decay theory of forgetting where the loss of memory is due to lapse of time and absence of rehearsal in that particular time period. Most aged patients with schizophrenia and with long standing institutionalization are not being exposed to the external environment, so they don't get the opportunity to rehearse their prior retained information that may also be one of the causes of memory impairment.

\section{Conclusion}

The finding of the index study suggests that the marked differences in cognitive impairment have been found between aged patient with schizophrenia and normal aged. Areas of impairment were recalling names of different things, general orientation and visuo-spatial coordination which may be problematic for aged population of schizophrenia because above mentioned deficits may result in difficulty in finding their way to their houses or work place and performing/executing the function to deliver the assigned task.

\section{REFERENCES}

1. Gold, J.M. \& Harvey, P.D. (1993) Cognitive deficits in schizophrenia; Psychiatric. Clinic of North America; 16, 295312.

2. Davidson, M. Harvey, P.D., \& Powchik, P.(1995) Severity of symptoms in geriatric chronic schizophrenic inpatients; Am. J. Psychiatry; 152, 197207.

3. Perlick, D., Mattis, S., \& Statsny, P. (1992) Neuropsychological discriminators of long-term inpatient or outpatient status in chronic schizophrenia; J. Neuropsychiatry Clin. Neurosci; 4, 428-434.

4. Wyatt, R.J. \& Hanter, I.D. (1998) The effects of early and sustained intervention on the long term morbidity on schizophrenia.; J Psychiatr Res; $32: 169-177$.

5. Jaeger, J., \& Douglas, E. (1992) Neuropsychiatric rehabilitation for persistent mental illness; Psychiat. Quart; 63, 71-93.

6. Meltzer, H.Y. \& McGurk, S.R. (1999) The effects of clozapine risperidone and olanzapine on cognitive functioning in schizophrenia; Schizophrenia. Bulletin., in press.

7. Harvey, P.D., Howanitz, E., Parrella, M., White, L., Hoblyn, J., Mohs, R.C. \& Davis, K.L., (1998) Cognitive adaptive and clinical symptoms in geriatric patients with lifelong schizophrenia: A comparative study across treatment sites; Am. J. Psychiatry; 155, 1080-1086Brink, T. L., Yesavage,
J.A.,Lum, O., Heersema, P.H.,Adey, M.,(1982)Screening tests for geriatric depression; Clinical Gerontologist, 1,37-43.

8. Harvey, P.D., Sukhodolsky, D., Parrella, M., White, L. \& Davidson, M. (1997c) The association between adaptive and cognitive deficits in geriatric chronic schizophrenic patients; Schizophrenia Research; 27,211-218.

9. Velligan, D.I., Mahurin, R.K., Diamond, P.L., Hazleton, B.C., Eckert, S.L. \& Miller,A.L., (1997) The functional significance of symptomotology and cognitive function in schizophrenia; Schizophrenia Research; 25, 2131.

10. Mueser,K.T., Bellack,A.S., Douglas, M.S., \& Wade,J.H.(1991)Prediction of social skills acquisition in schizophrenic and major affective disorder patients from memory and symptomotology; Psychiatric Research; 37, 281-296.

11. Corrigan, P.W., Wallace, C.J., Schade, M.I., Green, M.F., (1994) Cognitive dysfunctions and psychosocial skill learning in schizophrenia; Behaviour Therapy; 25, 5-15.

12. Lysaker, P., Bell, M. \& Beam-Goulet, J. (1995) Wisconsin Card Sorting Test and work performance in schizophrenia; Psychiatric Research; 56, 45-51.

13. Harvey, P.D., Lombardi, J., Leibman, M., White, L., Parrella, M., Powchik, P. \& Davidson, M. (1996) Cognitive impairment and negative symptoms in schizophrenia: A prospective study of their relationship; Schizophrenia Research; 22, 223-231.

14. Harvey, P.D., Parrella, M., White, L., Mohs, R.C. \& Davis, K.L. (1999a) The convergence of cognitive and adaptive decline in late-life schizophrenia; Schizophrenia Research., in press.

15. Goldberg, D. \& Williams, P. (1988) Manual of the General Health Questionnaire. winder; NFER-Nelson Park, D. C. (1992) Applied cognitive aging research; $\mathrm{Pp} 449-93$.

16. Kay,S.R., Opler,.L.A.,Lindenmayer,.J.P.(1987)The Positive and Negative Syndrome Scale (PANSS) for Schizophrenia; Schizophrenia bulletin; $13,261-276$

17. Park, D. C. (1992) Applied cognitive aging research; $\mathrm{Pp} 449-93$.

18. Craik, In., Fergus I. M.\& Salthouse, T.A. (1992)The Handbook of Aging and Cognition; Hillsdale, NJ: LEA; Pp 111-165.

19. Starr, J.M., Deary, I.J., Inch, S., Cross, S. \& MacLennan, W.J (1997) Age-associated cognitive decline in healthy old people; Age and Ageing. 